Researchers completing a study of liberal arts education sought to identify learning outcomes associated with both wisdom and citizenship. They have synthesized these themes

into seven outcomes that facilitate effective student learning and development.

By Patricia M. King, Marie Kendall Brown, Nathan K. LINDSAY, AND JONES R. VANHECKE

\title{
Liberal (Arts Student Learning Outcomes: An Integrated Approach
}

$\mathrm{T}$ HE OVERARCHING GOAL of a liberal arts education is to provide students with the necessary skills to construct lives of substance and achievement, helping them to become wise citizens. By offering programs and implementing practices that adopt an integrated and holistic approach to student learning outcomes, institutions of higher education may be better able to provide students with the necessary skills to achieve this goal. Nancy Thomas eloquently describes these initiatives as an effort to "cultivate in students the passion, balance, integrity, vision, and sense of collective responsibility that will prepare them for wise and ethical stewardship of their world" (p. 31). Further, as the needs of contemporary society have grown more diverse and complex, the purposes of a liberal arts education have experienced greater pressure to adapt to the changing world. James Freedman, president emeritus of the University of Iowa and Dartmouth College, asserts, "Liberal education ought to make a person independent of mind" and "skeptical of authority and received views" (p. 56). Martha Nussbaum, professor of law and ethics at the University of Chicago, argues that the purposes of a liberal arts education have evolved to better meet societal demands by reflecting the diverse and changing needs of contemporary society and that liberal education should involve "a cultivation of the whole human being for the functions of citizenship and life generally" (p. 9).

To carry out such visions of liberal education, colleges and universities are seeking to prepare students with skills that are not context-specific or bound by the limitations of our current understanding of known problems but that instead are applicable to new and changing contexts, expanding knowledge bases, and emerging issues.

In a 2005 national report, the American Association of Colleges and Universities (AAC\&U), a leading advocate for liberal education, clustered the overarching learning outcomes of today's colleges and universities in three groups (p. 6):

- Knowledge of human culture and the natural world (science, social sciences, mathematics, humanities, arts)

- Intellectual and practical skills (written and oral communication; inquiry, critical thinking, and creative thinking; quantitative literacy; information literacy; teamwork; integration of learning)

- Individual and social responsibility (civic responsibility and engagement; ethical rea- 
soning; intercultural knowledge and actions; propensity for lifelong learning)

The report offers supporting evidence for each outcome from the perspective of business and government leaders, faculty, and college students, which suggests that there is considerable consensus about the importance of these outcomes. However, according to this report, systematic national data and direct evidence of student progress toward these learning goals are only available for the knowledge outcomes and for a limited number of skill outcomes in the remaining two groups.

In essence, institutions of higher education now recognize that liberal education must do far more than help today's students attain knowledge. Unfortunately, many have yet to comprehensively enlarge their programs and practices to encompass the personal and social dimensions of learning and development. However, institutions can make purposeful progress toward creating the type of transformative educational paradigm set forth in Learning Reconsidered, a report jointly published by two leading organizations for student affairs professionals and edited by Richard Keeling. As the authors of this report explain, "In the transformative educational paradigm, the purpose of educational involvement is the evolution of multidimensional identity, including but not limited to cognitive, affective, behavioral, and spiritual development" (p. 9). Similar to the AAC\&U national report, Learning Reconsidered argues for putting student learning at the center of students' collegiate experiences in a way that recognizes the holistic nature of student development and the

Patricia M. King is professor of higher education at the Center for the Study of Higher and Postsecondary Education at the University of Michigan and a principal investigator for the Wabash National Study of Liberal Arts Education. Her email address is patking@umich.edu.

Marie Kendall Brown is a doctoral candidate at the Center for the Study of Higher and Postsecondary Education at the University of Michigan. Her research explores the multidimensional nature of intercultural development. Her e-mail address ismekendal@umich.edu.

Nathan K. Lindsay is a doctoral candidate at the Center for the Study of Higher and Postsecondary Education at the University of Michigan. His interests include teaching and learning improvement, technological issues, and international and comparative studies. His e-mail address is nlindsay@umich.edu.

JoNes R.VanHecke is dean of student life at Central College in Pella, Iowa. Her interests as a scholar and practitioner include citizenship, liberal arts education, and student development. Her e-mail address is vanheckej@central.edu.

We love feedback. Send letters to executive editor Marcia Baxter Magolda (aboutcampus@muohio.edu), and please copy her on notes to authors. importance of assessing learning outcomes associated with participation in these experiences.

Giving students a broad foundation of knowledge, skills that can be used across a range of contexts, and opportunities to see the connections among different domains of learning are the strategies that colleges and universities are using to prepare students to function effectively in today's complex world. Nancy Thomas offers the following synthesis of educational goals associated with liberal education: "A quality liberal education leads students to reflect on their place in the world and locate themselves historically and socially. ... Graduates of a liberal education need to be people of integrity possessed of a sense of responsibility to society. These qualities require a sense of humanity as well as a commitment to the common good with a conviction that there is something more important than oneself" (p. 30). Such an integrated and holistic approach to liberal education begins with the identification of specific outcomes that address the multiple dimensions of students' identities as well as the various expectations that institutions have for their graduates. In the next section, we discuss the process that we, as members of the research team for a national study of the liberal arts, used to make this identification.

\section{Defining the Seven Liberal Arts OUtCoMES OF THE Wabash NaTional Study of Liberal Arts Education}

HE WABASH NATIONAL STUDY of Liberal
Arts Education (WNSLAE) was designed to
explore the conditions and experiences that facilitate the achievement of liberal arts outcomes; each of us has been a member of this research team since its inception. For this study, we attempted to identify learning outcomes that, when considered together, embody the central principles of a liberal arts education. Our goal was to produce a list of liberal arts outcomes that connected the qualities of mind commonly associated with developing wisdom with the responsibilities of citizenship, meaning the educated person's commitment to community. Combining these foci, we envisioned an overarching conceptualization of developing wise citizens that would expand on the research at the Center of Inquiry in the Liberal Arts at Wabash College that sought to link these two lines of inquiry in the liberal arts.

We consulted the literature from a range of disciplinary perspectives to construct lists of student learning outcomes commonly associated with the liberal arts. We then used these lists to guide and validate a second literature review intended to organize these outcomes into a collective vision of a liberal arts education. As we 


\section{We view the seven learning outcomes as interdependent, mutually shaping one another, and part of a largeer developmental process taking place within the individual.}

read, we focused on the following questions: What is the outcome? How is it defined in the literature? How do we propose to define it? How is this outcome related to a liberal arts education? Although a variety of terms and phrases have been used to describe liberal arts outcomes, we found several thematic consistencies among many authors. We noted these and then refined our initial list several times, with the goal of reducing repetitiveness and creating useful thematic categories. While working to define and describe liberal arts outcomes, we jotted down phrases such as David Winter, David McClelland, and Abigail Stewart's “empathizing, recognizing one's own assumptions, and seeing all sides of an issue" (pp. 12-13) and Martha Nussbaum's "the capacity to reason logically, to test what one reads or says for consistency of reasoning, correctness of fact, and accuracy of judgment" (p. 10). Working with other members of the WNSLAE team from the Center of Inquiry in the Liberal Arts and the University of Iowa, we winnowed a long list of possible outcomes down to seven by weighing which best reflected the major tenets of liberal arts education and looking for thematic consistencies. During animated discussions, team members deliberated about when the overlap between categories merited finer conceptual distinctions and when such overlap illustrated the interdependent nature of liberal arts outcomes. For example, wrestling with nuances of terms, we chose to combine "inclination to inquire," "learning for self-understanding," and "attitudes and habits of mind" into a single outcome, "inclination to inquire and lifelong learning." In the end, we identified seven outcomes that, we believe, reflect the educational purposes associated with a liberal arts education. Our final list of liberal arts education outcomes and their definitions appears in Table 1.

\section{Relationships Among the Outcomes: An Integrated Perspective}

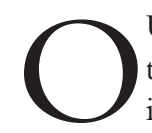
UR LIST of liberal arts outcomes has two distinguishing characteristics: the ways in which its elements are related and their developmental grounding. First, although these outcomes reflect dis- tinct attributes, they represent an integrated, holistic approach to liberal arts outcomes. We do not argue that these outcomes develop independently or that they are mutually exclusive. Rather, we view them as interdependent, mutually shaping one another, and part of a larger developmental process taking place within the individual. For example, being guided by moral standards that value fairness and caring for others (moral character) is an attribute that is associated with showing one's understanding of those different from oneself (intercultural effectiveness). Similarly, the skills associated with effective reasoning and problem solving are often associated with leadership skills. Seeing and understanding more than one perspective is required for the achievement of several outcomes, including problem solving, intercultural effectiveness, and the integration of learning. Being open to new ideas, a key attribute of the inclination to inquire, is likely to affect one's approach to general well-being-for example, one's willingness to learn about or to change lifestyle habits that affect one's health. This overlap among outcomes is one reason we chose to take the suggestion of Susan Jones and Marylu McEwen and depict them as if they were electrons in an atom, as shown in Figure 1.

Figure 1 illustrates the process of learning and development that results in the achievement of liberal arts outcomes as active movement within the developing individual, just as development itself reflects forward movement toward maturity. Our model supports the idea that some outcomes are more salient than others at given points in a student's education. For example, students' awareness of moral character or intercultural effectiveness may be heightened while taking classes with a service-learning component or when they have regular opportunities to discuss these issues in depth. Similarly, well-being may be more salient during periods of high stress (such as during examination periods), when confronted with a friend's drug or alcohol problem, or when preparing for an athletic event that requires a great deal of physical and mental preparation (for example, running a marathon).

The second distinguishing characteristic of these liberal arts outcomes is that each is viewed as multidimensional. As such, we argue that the achievement of each outcome requires integrating abilities across 
domains of development that have traditionally been separated. For example, rather than describing effective reasoning and problem solving as reflecting only cognitive skills, we agree with Robert Kegan that the ability to apply one's problem-solving skills requires maturity in intrapersonal and interpersonal domains as well as in the cognitive domain. Thus, there is value in defining each liberal arts outcome using this integrated perspective and, subsequently, in educating students in ways that also reflect all three dimensions. Drawing on Patricia King and Marcia Baxter Magolda's detailed example of such integration across developmental domains, which they detail in a recent article in the Journal of College Student Development, we offer an integrated perspective of the outcome we call "inclination to inquire and lifelong learning." The attributes and behaviors shown in Table 2 are consistent with those one would expect of a student who shows an advanced level of maturity on this outcome.

\section{EXAMPles OF STUdENT EXPERIENCES WITH THE LEARNING OUTCOMES}

$\mathrm{T}$ O ILLUSTRATE the multidimensional and interdependent nature of the learning outcomes on our list, we include verbatim examples from the WNSLAE pilot study in which college students discuss their experiences related to two of these outcomes.

Examples of the Intercultural Effectiveness Outcome. Thérèse, a second-year student studying human resources, describes how college classes have facilitated the broadening of her perspectives on living in a diverse world:

THÉRÈSE: And just by going to school and taking so many different classes where you're not so funneled into one direction, you have an opportunity to shape yourself as a more diverse person, you know. And that to me is, is probably one of the most important things is to be diverse, because our society's diverse. Our world is diverse. . . And I think going to school has made me really — just round myself out a little more.

INTERVIEWER: What do you think is important about being aware of that diversity?

THÉRÈSE: Um, being able to view somebody else's point differently, acceptance of one another. And, um, I just think that

\section{Table 1. Liberal Arts Outcomes, Wabash National Study of Liberal Arts Education}

Integration of learning is the demonstrated ability to connect information from disparate contexts and perspectives - for example, the ability to connect the domain of ideas and philosophies with the real world, one field of study or discipline with another, the past with the present, one part with the whole, the abstract with the concrete- and vice versa.

Inclination to inquire and lifelong learning reflects a strong desire to learn, ask questions, and consider new ideas. Such learning involves taking initiative to learn, not being satisfied with a quick answer, and possessing intrinsic motivation for intellectual growth. These dispositions lend themselves to a lifelong pursuit of knowledge and wisdom.

Effective reasoning and problem solving involves the capacity to make reflective judgments; think critically and independently; and analyze, synthesize, and evaluate information in order to make decisions and solve problems.

Moral character involves the capacity to make and act on moral or ethical judgments, treating others with fairness and compassion; this capacity includes several facets of morality: discernment, reasoning, motivation, and behavior.

Intercultural effectiveness includes knowledge of cultures and cultural practices (one's own and others'), complex cognitive skills for decision making in intercultural contexts, social skills to function effectively in diverse groups, and personal attributes that include flexibility and openness to new ideas.

Leadership entails the seven core values of Astin and his colleagues' Social Change Model for Leadership. Within the model, the core values fall into three categories: personal or individual values (consciousness of self, congruence, commitment), group values (collaboration, common purpose, controversy with civility), and a societal and community value (citizenship).

Well-being encompasses four dimensions: subjective, psychological, social, and physical. Subjective wellbeing is associated with happiness, life satisfaction, and life quality. Psychological well-being is the pursuit of meaningful goals and a sense of purpose in life. Social well-being refers to positive social health based on one's functioning in society. Finally, physical well-being is characterized by positive health-related attributes. 
there are a lot of things that could be said about really accepting people for who they are and recognizing the differences and not hating someone for their differences. Because you, you're really not going to make a society that way. [D27]

Thérèse says that college has taught her to be a wellrounded individual who values diversity (intrapersonal dimension). She thinks about contemporary issues in a more complex way (cognitive dimension), and she believes that she has gained communication skills and the ability to accept different others' perspectives (interpersonal dimension). Thérèse's experience illustrates the multidimensional nature of intercultural effectiveness as a collegiate outcome.

Morgan, a senior, has a strong sense of self, and many of her decisions and actions are internally motivated. This stage of development has come after a college experience characterized by exploration of her interests and identity and experimentation with different relationships and environments. In short, she exhibits a strong desire to understand these domains more comprehensively. She says that previously, she was very judgmental, but experiences such as dating someone outside her socioeconomic class have changed her perspective. She explains,

MORGAN: I've become more open-minded, and I've learned a lot, you know, particularly this year. And I don't want to give that up, and I know if I didn't go to college, I wouldn't have

Figure 1. Conceptualizing the Integrated Relationships Among Liberal Arts Outcomes

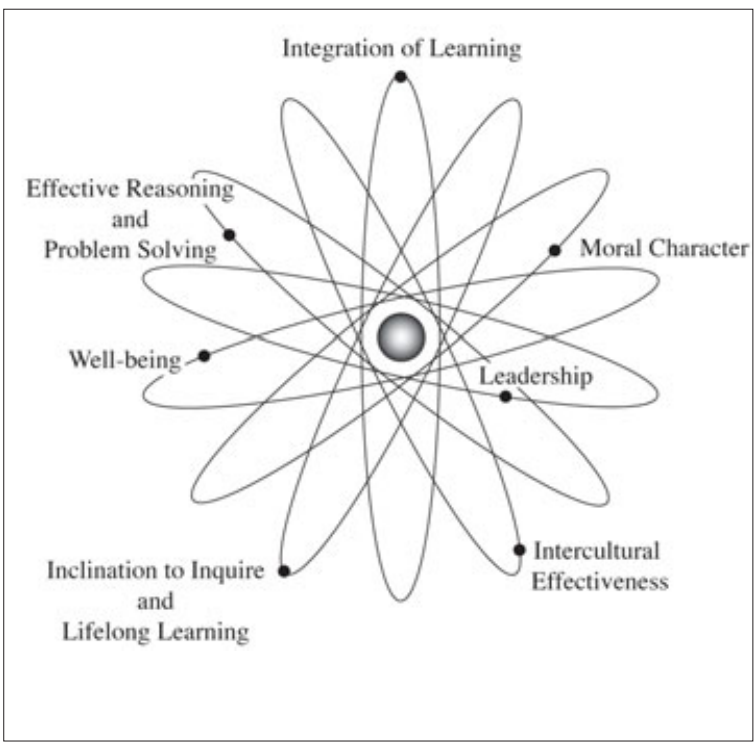

Source: Adapted from Jones, S. R., \& McEwen, M. K. (2000). A conceptual model of multiple dimensions of identity. Journal of College Student Development, 41(4), 409. had the same experience and I probably wouldn't have developed in the same way. It's just, just weird 'cause I thought I was going here so I could get a job [laughs].

INTERVIEWER: So how do you feel you've become more openminded?

MORGAN: Um, the way I see things. Like before, I was very judgmental. Um, judgmental of others and of myself, and like, I never really saw things a different way from my middle-class upbringing. And then I met a guy, and I dated [him] for a couple of months, and he was from a lower-class family. So just, and his outlook on life was so different from mine. So he helped me begin to see things differently. [CO5]

Morgan identifies her relationship with her boyfriend (interpersonal dimension) as a factor contributing to a shift in her perception of others (the cognitive dimension of intercultural effectiveness), and she notes how, as a result of this college experience, she has grown (intrapersonal dimension). Taken together, these elements reflect the multidimensional nature of the intercultural effectiveness outcome. Both Thérèse and Morgan are learning about different others through their collegiate experiences, and they are evaluating the importance of these interactions. Also, the preceding examples illustrate how development depends on a combination of personal attributes and environmental factors: flexibility and open-mindedness, coupled with stimulating and challenging classes, have facilitated their intercultural development. These examples also illustrate facets of other outcomes such as integration of learning (for example, connecting information from disparate contexts), inclination to inquire (for example, the desire to learn and ask questions, to consider alternate ideas), and effective reasoning (for example, the capacity to make reflective judgments and to think critically and independently). In this way, the examples illustrate the interdependent nature of these outcomes.

Examples of the Well-Being Outcome. Maria, a first-year student who is undecided about a major, describes how running contributed to her physical and psychological well-being. While she initially wanted to use exercise to avoid the dreaded "freshman fifteen," she has come to view running not only as a tool for weight maintenance but also as a way to clear her mind and reinvigorate herself-healthy stress management that enables her to focus better academically.

I run because I was on cross-country in high school, and it got to the point where now it's part of my routine. Like, if I feel tired or sluggish, it makes me feel happier [laughs] when I run. It's also like a release for me after class because it really helps me to clear my mind. 


\section{Table 2. Attributes and Behaviors Associated with High Inclination to Inquire and Lifelong LeARning, By Dimension of DeVelopment}

$\begin{array}{ll}\text { Cognitive } & \begin{array}{l}\text { Explores what is not understood; examines the basis of beliefs; acknowledges the evolving } \\ \text { nature of knowledge and continually examines forthcoming information; seeks opportuni- } \\ \text { ties to learn throughout life; understands both the big picture and the defining details of a } \\ \text { complex problem }\end{array} \\ \text { Intrapersonal } & \begin{array}{l}\text { Identifies and arranges priorities for intellectual inquiry; develops a personalized plan to pur- } \\ \text { sue these priorities; takes into consideration how further intellectual inquiry will affect who } \\ \text { one is, what one can do, and one's sense of self }\end{array} \\ \text { Interpersonal } & \begin{array}{l}\text { Uses relationships with others to share and gain knowledge and wisdom; seeks out multiple perspectives } \\ \text { based on others' experiences; strives to understand others' dispositions and motivations to learn, as well } \\ \text { as barriers to lifelong learning }\end{array}\end{array}$

Like, um, I just go, and I'll run for half an hour, 45 minutes, and I just won't think about anything, you know. Then I can come back and focus on what I have to do later after I do that. [B30]

Another student, Alyssa, a senior in astronomy, says that she has learned to manage the academic stress of college by prioritizing and making good decisions. When asked about the ways in which she takes care of herself, she explains,

$\mathrm{Um}$, in general, now I try to, like, get to all my classes and stay on top of things. I think that school has become important to my emotional well-being, to some degree. I feel like if I'm not on top of things and they get out of control, then I lose control. Then I'm, like, what the hell, you know, and then it's a bad thing for me. So I usually, I go to most all my classes and I try to keep up with all my work. Um, I try to really keep in touch with, like, my friends, especially my astronomy friends, you know, to make sure that I'm not just letting myself flow into a bad mood or something like that. I definitely have to make an effort not to isolate myself, you know, because I'm more like a quiet person, so it's easy for me to isolate myself. In order to take care of myself, I try to really stay in contact with people and stay on top of everything. That's pretty much what I do to take care of myself. [B42]

Alyssa has learned that taking care of herself is a multifaceted endeavor. She understands that attending class and being a diligent student affects her emotional wellbeing. She also recognizes that connecting socially with others has a positive impact on her psychological health. For Alyssa, a thoughtful and introspective student, these insights came about after reflecting on the many aca- demic and mental health challenges she had faced in her early college years. By using effective reasoning and problem-solving strategies about the causes of these initial difficulties ("a progression of me realizing, like, where my limits were"), she altered unproductive and unhealthy behaviors and has since made it her credo to "be really on top of things." She concludes,

Because of how great it feels to be really on top of things again, I would like to continue feeling this great, you know? So now, whenever I think, "Oh, I don't wanna go to class" or whenever I don't feel like waking up in the morning, I always measure that against how great it feels to, you know, like, how bad it feels the other way, too. [B42]

For both Maria and Alyssa, achieving well-being in college is related to a variety of factors, and these students rely on their problem-solving and reasoning capacities to make sense and learn from their experiences. In both examples, the interconnectedness of the learning outcomes is apparent.

\section{Ten Strategies for Practicing Integrated Liberal ARTs Education}

$\mathrm{S}$ TUDENT AFFAIRS EDUCATORS, faculty, staff, and administrators who strive to create programs and practices that promote the kind of integrated approach presented in this article will ultimately educate students about the multifaceted nature of their world. Educators who maintain a unidimensional approach to student development (for example, those who focus on one dimension, such as only cognitive development or only social development) risk providing students with unidimensional experiences and measuring learning outcomes in unidimensional ways. Given this risk, we need to incorporate the seven learning outcomes in every aspect of the institution and 
make a commitment to integrating them into our work every day. This is a task that can't be hastily undertaken in preparation for an accreditation visit or as a simple precursor to applying for a grant. Developing programs and experiences that promote holistic student development both in and out of the classroom requires concentrated effort and unilateral institutional commitment. Although the following list is far from exhaustive, we offer ten strategies for incorporating liberal arts learning outcomes into the fabric of an institution:

1. Incorporate institutional learning outcomes more widely than just in mission and vision statements, using myriad opportunities to show how the outcomes are related to each other and to students' long-term goals, as well as why they are central to the institution. The learning outcomes should be integrated into institutional strategic and operational plans and featured in goal setting and program evaluation as well.

2. Use a campuswide approach by encouraging everyone to work together to infuse holistic student development across outcomes into every aspect of student learning. This crucial work should occur in the spaces between academic affairs and student affairs as well as within each of these areas. It is valuable for students to receive a consistent message from multiple points of contact across campus. The more that students hear about these interdependent outcomes from different people at different times and in different places, the more likely students will be to engage with them.

3. Seize or create opportunities to talk about what these outcomes mean at the institutional level. While it is important to have a broad definition of each learning outcome, it is even more critical to know how a specific college or university defines and interprets each outcome. In other words, what do we at Bluegrass University or Meadow Wood College mean when we talk about leadership, intercultural effectiveness, or moral character? How do the institution's values shape our understanding of each learning outcome, and how do we communicate this to our students?

4. Make a significant commitment to the integrated model by focusing on one or two outcomes each year, perhaps in the form of a theme for the year. Realistically, colleges and universities can't incorporate new initiatives for each learning outcome immediately. Because the outcomes are interdependent and mutually shape one another, institutions can alternate the focus without hindering student growth.

5. Use the multidimensional nature of learning outcomes and an understanding of the importance of integration of learning across domains to develop student expectations. For example, what specific goals does the institution have for student development in the area of effective reasoning and problem solving, well-being, or integration of learning?

6. Make the outcomes accessible to everyone on campus. Include the outcomes in the banner of electronic correspondence, paint them in public places, post them in classrooms and residence halls, incorporate them into syllabi, or print them on institutional items that are given to everyone, such as pencils or T-shirts. These are just a few suggestions for putting the concepts in front of the entire community. This kind of passive education can also yield results as a conversation starter.

7. Use the integrated model and the seven learning outcomes as topics for community conversations. Build discussions of the learning outcomes into first-year and senior seminars, orientation conversations, and advising appointments. Consider using the outcomes framework to shape developmental transcripts or portfolios.

8. Build educational programming in residence halls around an outcomes rubric. For example, ask hall directors and resident assistants to creatively engage students in discussions on lifelong learning, intercultural effectiveness, or well-being. Kathleen Kerr and James Tweedy's recent About Campus article provides an excellent example of a rubric for citizenship education in residence halls. The rubric organizes the competencies not only by topical focus but also by year of enrollment, so that more complex competencies are explored with junior and senior students. 
9. Focus campuswide teach-ins on topics related to the interdependent nature of the outcomes, integration of learning across domains, or individual student learning outcomes. Such activities may provoke insightful discussions about how to further infuse the curriculum and cocurriculum with integrated student learning outcomes.

10. Invite educators to campus to help facilitate conversations and reflective thinking on these ideas as a part of your institution's commitment to ongoing professional development. Outside voices (for example, educators who have tried to achieve similar learning goals, employers or civic leaders looking for college graduates with the skills embodied in the learning outcomes) can lend support for the work already accomplished and provide critical perspectives to help shape future efforts.

These strategies can be incorporated into ongoing planning, programming, and professional development efforts, and many can be implemented with little or no additional funding. The key is to commit to working together on campus and getting started on these initiatives.

\section{Conclusion}

\section{$\mathrm{T}$} HE SEVEN LEARNING OUTCOMES represent important components of American higher education and are central to the mission of many colleges and universities. As institutions of higher education help students become wise citizens who embrace education not only as a benefit for themselves but also as a gift for the betterment of the public good, they should strive for development in multiple outcomes. The demands of the twenty-first century require simultaneous growth in all seven outcomes. Each institution should consider how its educators can more effectively apply an integrated perspective to curricular and cocurricular initiatives. The success of institutions in promoting student learning and development depends on finding ways to unite learning outcomes into a comprehensive plan for practice and assessment. While ambitious and intricately interconnected, the purposes of a contemporary liberal arts education remain at the heart of constructing lives of substance.

\section{Notes}

Association of American Colleges and Universities. (2005). Liberal education outcomes: A preliminary report on student achievement in college. Washington, DC: Author.

Astin, A. W., Astin, H. S., Boatsman, K. C., BonousHammarth, M., Chambers, T., Goldberg, L. S., Johnson, C. S., Komives, S. R., Langdon, E. A., Leland, C., Lucas, N., Pope, R. L., Roberts, D., \& Shellogg, K. M. (1996). A social change model of leadership development: Guidebook (Version 3). Los Angeles: University of California, Higher Education Research Institute.

Freedman, J. O. (2003). Liberal education and the public interest. Iowa City: University of Iowa Press.

Jones, S. R., \& McEwen, M. K. (2000). A conceptual model of multiple dimensions of identity. Journal of College Student Development, 41(4), 405-414.

Keeling, R. P. (Ed.). (2004). Learning reconsidered: A campuswide focus on the student experience. Washington, DC: National Association of Student Personnel Administrators \& American College Personnel Association.

Kegan, R. (1994). In over our heads: The mental demands of modern life. Cambridge, MA: Harvard University Press.

Kerr, K. G., \& Tweedy, J. (2006). Beyond seat time and student satisfaction: A curricular approach to residential education. About Campus, 11(5), 9-15.

King, P. M., \& Baxter Magolda, M. (2005). A developmental model of intercultural maturity. Journal of College Student Development, 46(6), 571-592.

Nussbaum, M. (1997). Cultivating humanity: A classical defense of reform in liberal education. Cambridge, MA: Harvard University Press.

Thomas, N. (2002). In search of wisdom: Liberal education for a changing world. Liberal Education, 88(4), 28-33.

Turner, F. M. (Ed.). (1996). The idea of the university: John Henry Newman. New Haven, CT: Yale University Press.

Winter, D. G., McClelland, D. C., \& Stewart, A. J. (1981). A new case for the liberal arts. San Francisco: Jossey-Bass.

The authors gratefully acknowledge the contributions of the Center of Inquiry in the Liberal Arts at Wabash College in support of this project. For further information, visit

http://www.liberalarts.wabash.edu/nationalstudy. 